\title{
Effect of Working Temperature of Energy Saving Adsorption Refrigeration System on COP by Numerical Simulation
}

\author{
Zeqin Liu ${ }^{123, \text { a }}$, Hongtao $\mathrm{Du}^{3}$ and Ning Wang ${ }^{3}$ \\ ${ }^{1}$ Engineering Research Center of Freezing and Cold Storage Technology, Ministry of Education, \\ Guangrong Road No.409, Beichen District, Tianjin , 300134 , China \\ ${ }^{2}$ Tianjin Key Laboratory of Refrigeration Technology, Guangrong Road No.409, Beichen District, \\ Tianjin , 300134 , China \\ ${ }^{3}$ College of Mechanical Engineering, Tianjin University of commerce, Guangrong Road No.409, \\ Beichen District, Tianjin , 300134 , China \\ aliuzq@tjcu.edu.cn
}

Keywords: adsorption refrigeration, basic cycle, COP, numerical simulation

Abstract. The development of the adsorption refrigeration technology was relatively slow, and the COP of the adsorption refrigeration system usually indicated as 0.2 to 0.3 only in experimental reports. The lower refrigerating efficiency (COP) of the adsorption refrigeration technology has become the bottleneck of the commercialization development compared with other refrigeration technologies [1]. The mathematical model of the basic cycle of adsorption refrigeration system was established for this study, and the adsorption refrigeration system performance variation was simulated by MATLAB software. When the evaporating temperature were set as a constant $4^{\circ} \mathrm{C}$ and the condensing temperature as $34^{\circ} \mathrm{C}$, the numerical simulation of the basic cycle of the adsorption refrigeration was carried out to explore the variation of the desorption temperature and the COP of the cycle of the adsorption refrigeration system. It was found that, when the simulated condition of the adsorbent temperature $\mathrm{T}_{\mathrm{a} 2}=6^{\circ} \mathrm{C}$, the COP of the cycle of the adsorption refrigeration system increased from 0.257 to 0.502 with the variation of the desorption temperature $\mathrm{T}_{\mathrm{g} 2}$ increasing from $70^{\circ} \mathrm{Cto} 98^{\circ} \mathrm{C}$. And when the simulated condition of the desorption temperature $\mathrm{T}_{\mathrm{g} 2}=95^{\circ} \mathrm{C}$, the COP of the cycle of the adsorption refrigeration system decreased from 0.454 to 0.273 with the variation of the absorbent temperature $\mathrm{T}_{\mathrm{a} 2}$ increased from $2^{\circ} \mathrm{C}$ to $40^{\circ} \mathrm{C}$.

\section{Introduction}

With the continuous progress of science and technology development, people's demand on the quality of life highly increased, and for most of the times of human activities were in the interior of the building, the indoor environment quality requirements were also getting higher and higher. However, the traditional refrigeration which provide a comfortable environment for mankind can not only eliminate the consumption of energy, the refrigerant used for refrigeration can cause pollution to the environment, and the greenhouse effect and ozone empty that caused by the use of HCFC refrigerant were becoming more and more serious, which greatly threat the human living environment. Therefore, the development of new non-polluting refrigerant and new refrigeration method were imminent.

The research of adsorption refrigeration was reported by academia in 1848, and after that, the adsorption refrigeration got some development in the direction of the business [2]. But in its early stage of development, adsorption refrigeration had many disadvantages that cannot be solved satisfactorily, and the adsorption refrigeration products promotion was restricted [3]. In 1992, the international refrigeration industry experts and scholars held the first international solid adsorption refrigeration assembly in Paris, and adsorption refrigeration technology came back into people's vision, and attracted much attention [4,5]. As a kind of new green energy application technology, adsorption refrigeration technology had great potential for development. 


\section{Mathematical Model of Basic Adsorption Refrigeration}

\section{The Mathematical Model of Basic Cycle of Adsorption Refrigeration [6]}

When the working medium heated in adsorbent bed was as same as those which was cooled, the calculation of the seven kinds of heat was as follows:

(1) $\mathrm{Q}_{\mathrm{h}}$ — the sensible heat absorbed by the bed during isometric pressurization process

$$
\mathrm{Q}_{\mathrm{h}}=\int_{T_{g 2}}^{T_{g 1}} \mathrm{C}_{\mathrm{a}}(T) M_{a} d T+\int_{T_{g 2}}^{T_{g 1}} C_{l c}(T) M_{a} x_{a 2} d T+\int_{T_{g 2}}^{T_{g 1}} C_{m}(T) M_{m} d T
$$

And,

$$
m_{c}=X_{\text {conc }} \times m_{a}
$$

Where, ${ }^{\mathrm{C}_{\mathrm{a}}}(T)$ was specific heat of adsorbent, $\mathrm{kJ} /(\mathrm{kg} \cdot \mathrm{K}) ;{ }^{\mathrm{C}_{\mathrm{lc}}}(T)$ was specific heat of refrigerant liquid, $\mathrm{kJ} /(\mathrm{kg} \cdot \mathrm{K}) ;{ }^{M_{a}}$ was mass of adsorbent, $\mathrm{kg} ;{ }^{M_{m}}$ was mass of refrigerant, $\mathrm{kg}$.

(2) $\mathrm{Q}_{\mathrm{g}}$ __ heat for desorption process

$$
\mathrm{Q}_{\mathrm{g}}=\int_{T_{g 1}}^{T_{g 2}} \mathrm{C}_{\mathrm{a}}(T) M_{a} d T+\int_{T_{g 1}}^{T_{g 2}} C_{l c}(T) M_{a} x d T+\int_{T_{g 1}}^{T_{g 2}} C_{m}(T) M_{m} d T-\int_{T_{g 1}}^{T_{g 2}} M_{a} h_{d} d x
$$

Where, ${ }^{h}$ was heat of adsorption, $\mathrm{kJ} / \mathrm{kg}$.

(3) $Q_{c}$ the sensible heat taken away during the isometric cooling process of the bed

$$
\mathrm{Q}_{\mathrm{c}}=\int_{T a 1}^{T_{\mathrm{g} 2}} \mathrm{C}_{\mathrm{a}}(T) M_{a} d T+\int_{T_{a 1}}^{T_{\mathrm{g} 2}} C_{l c}(T) M_{a} x_{d 2} d T+\int_{T a 1}^{T_{g 2}} C_{m}(T) M_{m} d T
$$

(4) $Q_{a d}$ _the heat taken away by cold source in the adsorption process

$$
\mathrm{Q}_{\mathrm{ad}}=\int_{T_{a 2}}^{T_{a 1}} \mathrm{C}_{\mathrm{a}}(T) M_{a} d T+\int_{T_{a 2}}^{T_{a 1}} C_{l c}(T) M_{a} x d T+\int_{T_{a 2}}^{T_{a 1}} C_{m}(T) M_{m} d T+\int_{T_{a 2}}^{T_{a 1}} M_{a} h_{d} d x-\int_{0}^{T_{a}-T_{e}} C_{p c}(T) M_{a} \Delta x d T
$$

(5) $Q_{\text {ref —_efrigeration effect }}$

$Q_{\text {ref }}=M_{a} L_{c} \Delta x$

Where, $L_{c}$ was latent heat of evaporation of refrigerant, $\mathrm{kJ} / \mathrm{kg} ; \Delta x$ was adsorption capacity (kg-refrigerant/kg-adsorbent) .

(6) $Q_{\text {cond }}$ heat for condensation process

$$
\mathrm{Q}_{\text {cond }}=M_{a} L \Delta x+\int_{T_{c}}^{T_{g}} C_{p c}(T) M_{a} \frac{d x}{d T} d T
$$

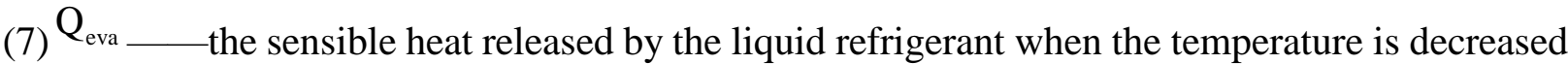
from the condensing temperature $\left(\mathrm{T}_{\mathrm{c}}\right)$ to evaporation temperature $\left(\mathrm{T}_{\mathrm{e}}\right)$

$$
\mathrm{Q}_{\mathrm{eva}}=\int_{T_{c}}^{T_{e}} C_{l c}(T) M_{a} \Delta x d T
$$

Where, $T_{e}$ was evaporation temperature, $\mathrm{K} ; T_{c}$ was condensing temperature, $\mathrm{K}$. 
COP (Coefficient of Performance) and SCP (Specific Cooling Power) can be used as the system evaluation criteria, and their calculations are listed as follow:

$$
\begin{aligned}
& C O P=\left(Q_{\text {ref }}-Q_{\text {eva }}\right) /\left(Q_{h}+Q_{g}\right) \\
& S C P=Q_{\text {ref }} /\left(t_{\text {cycle }} m_{c}\right)
\end{aligned}
$$

Where, ${ }^{m_{c}}$ was mass of refrigerant, $\mathrm{kg} ;{ }^{t}$ cycle was the cycle time of adsorbent bed, $\mathrm{s}$.

\section{The Results of Numerical Simulation and Analysis}

\section{The Effect of Desorption Temperature on COP}

A numerical simulation was carried on through MATLAB in order to solve the relationship between the desorption temperature $\mathrm{T}_{\mathrm{g} 2}$ and $\mathrm{COP}$, and special boundary conditions were given as follows: desorption temperature $\mathrm{T}_{\mathrm{g} 2}$ was varied in the range of $70^{\circ} \mathrm{C} \sim 98^{\circ} \mathrm{C}$, adsorption temperature of $\mathrm{T}_{\mathrm{a} 2}$ was $6^{\circ} \mathrm{C}$, evaporation temperature $\mathrm{T}_{\mathrm{e}}$ was $4^{\circ} \mathrm{C}$, and condensing temperature $\mathrm{T}_{\mathrm{c}}$ was $34^{\circ} \mathrm{C}$. Simulation results are showed in Fig. 1.

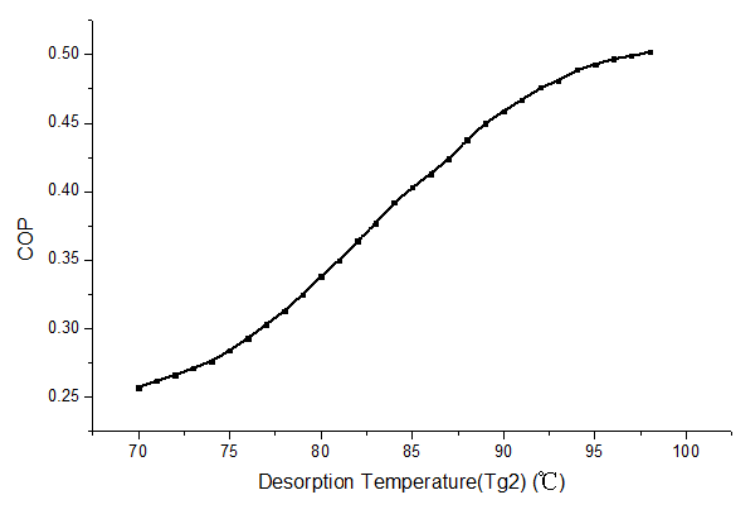

Fig. 1 The effect of desorption temperature on COP

As is shown in Fig. 1, when the desorption temperature $\mathrm{T}_{\mathrm{g} 2}$ gradually increased from $70^{\circ} \mathrm{C}$ to $98^{\circ} \mathrm{C}$, circulating COP of adsorption refrigeration system also increased from 0.257 to 0.502 , but its trend increased more slowly. This is because with the increase of desorption temperature $\mathrm{T}_{\mathrm{g} 2}$, the desorption of adsorbent was more and more fully, which means more and more adsorbate were desorbed; however, the sensible heat load was not only used to provide the energy for desorption, but also used to heat up the adsorption bed and other inert materials and this part of sensible heat was much bigger and bigger. Therefore, the COP of the cycle will gradually increase when the desorption temperature $\mathrm{T}_{\mathrm{g} 2}$ gradually increased from $70^{\circ} \mathrm{C}$ to $98^{\circ} \mathrm{C}$, but the increase was getting smaller and smaller.

\section{The Effect of Adsorption Temperature on COP}

In order to solve the relationship between adsorption temperature $\mathrm{T}_{\mathrm{a} 2}$ and $\mathrm{COP}$ of adsorption refrigeration system, a numerical simulation was carried on using MATLAB, and special boundary conditions were given as follows: adsorption temperature $\mathrm{T}_{\mathrm{a} 2}$ was varied in the range of $2^{\circ} \mathrm{C}$ to $40^{\circ} \mathrm{C}$, desorption temperature $\mathrm{T}_{\mathrm{g} 2}$ was $95^{\circ} \mathrm{C}$, evaporation temperature $\mathrm{T}_{\mathrm{e}}$ was $4^{\circ} \mathrm{C}$, and condensing temperature $\mathrm{T}_{\mathrm{c}}$ was $34^{\circ} \mathrm{C}$ and simulation results were showed in Fig. 2. 


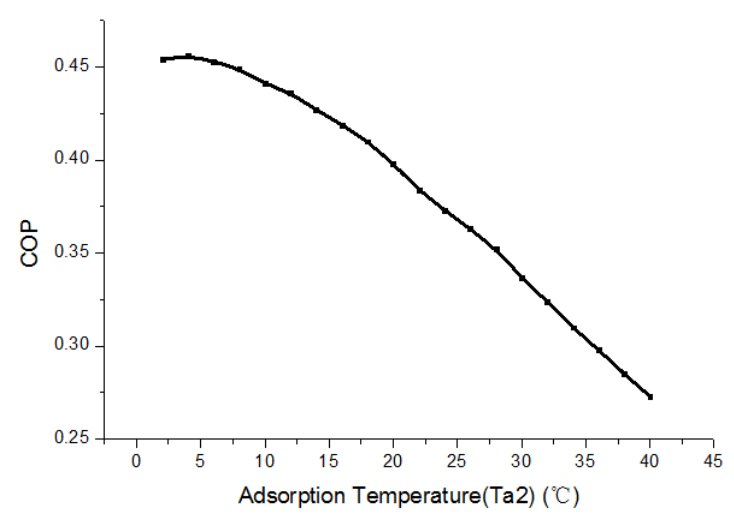

Fig. 2 The effect of adsorption temperature on COP

As it can be seen from Fig. 2, with the adsorption temperature $\mathrm{T}_{\mathrm{a} 2}$ gradually increased from the 2 ${ }^{\circ} \mathrm{C}$ to $40{ }^{\circ} \mathrm{C}$, adsorption refrigeration cycle system COP was gradually reduced from 0.454 to 0.273 . This is because with increasing of adsorption temperature $\mathrm{T}_{\mathrm{a} 2}$, the difference between the initial adsorption temperature $\mathrm{T}_{\mathrm{a} 1}$ and adsorption temperature $\mathrm{T}_{\mathrm{a} 2}$ gradually decreased; at the same time, more and more refrigerant was adsorbed by adsorbent, which resulted in decrease of adsorption capacity, and led to decrease of COP.

\section{Conclusions}

1) Under the simulation conditions that adsorption temperature $\mathrm{T}_{\mathrm{a} 2}$ was $6^{\circ} \mathrm{C}$, evaporation temperature $\mathrm{T}_{\mathrm{e}}$ was $4^{\circ} \mathrm{C}$, and condensing temperature $\mathrm{T}_{\mathrm{c}}$ was $34^{\circ} \mathrm{C}$, when desorption temperature $\mathrm{T}_{\mathrm{g} 2}$ gradually increased from $70^{\circ} \mathrm{C}$ to $98^{\circ} \mathrm{C}$, the $\mathrm{COP}$ of adsorption refrigeration system gradually increased from 0.257 to 0.502 .

2) Under the simulation conditions that desorption temperature $\mathrm{T}_{\mathrm{g} 2}$ was $95^{\circ} \mathrm{C}$, evaporation temperature $\mathrm{T}_{\mathrm{e}}$ was $4^{\circ} \mathrm{C}$, and condensing temperature $\mathrm{T}_{\mathrm{c}}$ was $34^{\circ} \mathrm{C}$, when adsorption temperature $\mathrm{T}_{\mathrm{a} 2}$ gradually increased from $2^{\circ} \mathrm{C}$ to $40^{\circ} \mathrm{C}$, the COP of adsorption refrigeration system gradually reduced from 0.454 to 0.273 .

\section{Acknowledgement}

The study was supported by Tianjin Municipal Natural Science Foundation under the contract No. 13JCZDJC27400.

\section{References}

[1]. LI T X, WANG R Z, WANG L W. High-efficient thermo-chemical sorption refrigeration driven by low-grade thermal energy. Chin Sei Bull. 2009, 54(6): 885 905.

[2]. Wen Wang, Ruzhu Wang, et al. Analysis of Solid Adsorption Refrigeration Cycle. Journal of Chemical Industry and Engineering, 1999, 50(5): 714-718. In Chinese

[3]. Guo Wei, Xuesheng Wang, et al. Research Development of Heat Transfer Enhancement in Adsorption Refrigeration. Energy Technology, 2007, 28(2): 105-109, 114. In Chinese

[4]. Yunzhuang Lu, Ruzhu Wang, Zhoushu Jiang. Solid Adsorption Refrigeration and Its Development. Energy Technology. 2001, 22(3): 92. In Chinese

[5]. Wenzhuo An, Zeqin Liu, Feng Pei. Experimental study and exploration of adsorption working pair in adsorption refrigeration system. Cryogenics\&Superconductivity. 2012, 41(3): 67. In Chinese

[6]. Yukun Fen, Xiao Yang, Lianxiang Ma. Modeling and Analysis of Basic Chemical Adsorption Refrigeration Cycle. Sciencepaper Online. In Chinese 